\title{
Effects of process variables and kinetics on the degradation of 2,4- dichlorophenol using advanced reduction processes (ARP)
}

\author{
Xingyue $\mathrm{Yu}^{\mathrm{a}, \mathrm{b}}$, Deirdre Cabooter ${ }^{\mathrm{a}}$, Raf Dewil ${ }^{\mathrm{b}, *}$ \\ ${ }^{a}$ KU Leuven, Department of Pharmaceutical and Pharmacological Sciences, Pharmaceutical Analysis, Herestraat 49, B-3000 Leuven, Belgium \\ ${ }^{\mathrm{b}} \mathrm{KU}$ Leuven, Department of Chemical Engineering, Process and Environmental Technology Lab, J. De Nayerlaan 5, B-2860 Sint-Katelijne-Waver, Belgium
}

\section{A R T I C L E I N F O}

\section{Keywords:}

2,4-Dichlorophenol

Advanced Reduction Processes

Degradation kinetics

\begin{abstract}
A B S T R A C T
This study aims at investigating the efficiency and kinetics of 2,4-DCP degradation via advanced reduction processes (ARP). Using UV light as activation method, the highest degradation efficiency of 2,4-DCP was obtained when using sulphite as a reducing agent. The highest degradation efficiency was observed under alkaline conditions $(\mathrm{pH}=10.0)$, for high sulphite dosage and UV intensity, and low 2,4-DCP concentration. For all process conditions, first-order reaction rate kinetics were applicable. A quadratic polynomial equation fitted by a Box-Behnken Design was used as a statistical model and proved to be precise and reliable in describing the significance of the different process variables. The analysis of variance demonstrated that the experimental results were in good agreement with the predicted model $\left(\mathrm{R}^{2}=0.9343\right)$, and solution $\mathrm{pH}$, sulphite dose and UV intensity were found to be key process variables in the sulphite/UV ARP. Consequently, the present study provides a promising approach for the efficient degradation of 2,4-DCP with fast degradation kinetics.
\end{abstract}

\section{Introduction}

Chlorophenols are environmental pollutants that are frequently encountered in industrial effluents originating from the production of pharmaceuticals, herbicides and dying textiles [1-3]. 2,4-Dichlorophenol $(2,4-\mathrm{DCP})$ is a representative chlorophenol that is regularly present in chemical industry wastewater [4]. It is known for its high persistence in water systems and is highly toxic, xenobiotic and carcinogenic [5]. As a result, much attention has been paid to the development of methods to remove 2,4-DCP from wastewater [6-9]. Conventional methods, such as biological treatment processes, are not suitable for 2,4-DCP removal due to the toxicity of 2,4-DCP for microorganisms and its non-biodegradable inhibitory properties [10]. In recent years, waste streams containing 2,4-DCP are most commonly treated via physical separation processes [11], such as membrane filtration or evaporation. However, these methods do not result in the degradation of the component, but rather in its concentration in a secondary stream, which requires additional treatment. Therefore, some chemical treatments have been developed to effectively degrade recalcitrant organic matter, such as advanced oxidation processes (AOPs) $[12,13]$. Although being highly effective in the degradation of halogenated organic compounds without introducing secondary waste problems [14,15], AOPs can generate oxidation products with a higher toxicity than the parent compound [16-18]. Consequently, it is vital to find an efficient way to control and optimize the degradation of 2,4DCP in the treatment process $[11,19]$.

A novel group of treatment methods, termed Advanced Reduction Processes (ARPs), combine activation methods with reducing agents to produce electron-rich free radicals that are able to efficiently destroy oxidized target contaminants. It has been reported that ARPs show great potential in degrading aliphatic halogenated organic components, such as 1,2-dichloroethane [20], vinyl chloride [21], and monochloroacetic acid [22]. Other publications report that ARPs are successful in removing inorganic disinfection by-products from drinking water [23]. The advantage of ARPs is that they destroy the target contaminants directly by converting them into simple and biodegradable by-products, instead of transferring them to another phase or generating intermediates with a higher toxicity [24,25]. Several activation methods have been tested in previous studies, such as ultraviolet (UV) irradiation, high energy electron beam and ultrasound. Among these methods, UV light has been found to be the most economic and effective in promoting the production of reductive radicals [26,27]. In this study, low-pressure UV-light at a wavelength of $253.7 \mathrm{~nm}$ will be applied in combination with three different reductants (dithionite, sulphide, and sulphite), leading to the formation of various reactive radicals. These radicals have been demonstrated to be responsible for the degradation of halogenated aromatic pollutants. The formation reactions of the radicals are given by the following equations [28-31]:

\footnotetext{
* Corresponding author.

E-mail address: raf.dewil@kuleuven.be (R. Dewil).
} 
UV/dithionite ARP: $\mathrm{S}_{2} \mathrm{O}_{4}{ }^{2-}+\mathrm{ho} \rightarrow 2 \mathrm{SO}_{2} \cdot{ }^{-}$(sulphur dioxide radical)

UV/sulphide ARP: $\mathrm{HS}^{-}+$ho $\rightarrow \mathrm{HS}^{-}{ }^{-}$(bisulphide ion)

UV/sulphite ARP: $\mathrm{SO}_{3}{ }^{2-}+\mathrm{ho} \rightarrow \mathrm{e}_{\mathrm{aq}}{ }^{-}+\mathrm{SO}_{3} \cdot$

The objective of this study is to investigate the kinetics and efficiency of 2,4-DCP degradation using sulphite, dithionite and sulphide as reducing agents in combination with UV and to determine the influence of the most important process parameters, such as solution $\mathrm{pH}$, sulphite dosage, initial 2,4-DCP concentration and UV light intensity. Additionally, a multivariate statistical model is developed to (i) evaluate the relationship between the response variable (degradation efficiency) and the process parameters, and (ii) to identify the optimal value of each variable for maximum 2,4-DCP degradation.

\section{Materials and methods}

\subsection{Chemicals}

2,4-Dichlorophenol (2,4-DCP, analytical grade, purity $\geq 99.0 \%)$ was purchased from Alfa Aesar (Karlsruhe, Germany); sodium sulphite $\left(\mathrm{Na}_{2} \mathrm{SO}_{3}\right)$ and sodium dithionite $\left(\mathrm{Na}_{2} \mathrm{~S}_{2} \mathrm{O}_{4}\right)$ were purchased from Fisher Chemical (Leicester, UK); and sodium sulphide $\left(\mathrm{Na}_{2} \mathrm{~S}\right)$ was purchased from Acros Organics (Geel, Belgium). All chemicals and solvents were at least of analytical grade and used as obtained, without further purification. Milli-Q ultra-pure water was used for dissolution, dilution and to prepare the mobile phases. Methanol (Acros Organics, Geel, Belgium) was HPLC grade.

\subsection{Experimental procedure}

All UV irradiation experiments were carried out in a cylindrical photo-reactor of $1 \mathrm{~L}$ with an active volume of $800 \mathrm{~mL}$. A schematic diagram of the photo-reactor is added in Fig. 1. The inner diameter of the reactor was $93 \mathrm{~mm}$. A quartz tube with an outer diameter of $47 \mathrm{~mm}$ was located centrally in the reactor for the placement of the UV lamp, thus the maximum physical path length of the UV waves in the reactor was $23 \mathrm{~mm}$. The height of the reactor was approximately $240 \mathrm{~mm}$. The reaction mixture was continuously stirred using a magnetic bar stirrer. The light source was a low-pressure UV mercury lamp (Phillips TUV PLL), which emitted UV radiation, mainly at a wavelength of approx. $254 \mathrm{~nm}$. Cooling water was continuously circulated around the reactor to control the temperature of the system during the experiments.

The 2,4-DCP degradation was followed as a function of time for all treatments. Batch experiments were conducted with three reductive reagents (sulphite, dithionite and sulphide) to compare their abilities in degrading 2,4-DCP and to select the most promising reductant for further study. Blank experiments were carried out by applying UV irradiation and reductive agent addition separately to provide a basis for comparison of the combined ARP (reductive agent/UV) treatment. The influence of various experimental parameters on 2,4-DCP degradation efficiency and kinetics were investigated. These parameters included solution $\mathrm{pH}(3.0,5.0,7.0,9.0,10.0)$, reductive agent dosage $(1,2,5,8$, $16 \mathrm{mM})$, initial 2,4-DCP concentration $(0.12,0.28,0.60,1.00 \mathrm{mM})$ and UV intensity $\left(900,2000,3200 \mu \mathrm{W} / \mathrm{cm}^{2}\right.$, calculated based on the diameter of the quartz tube surrounding the lamp). $0.1 \mathrm{M} \mathrm{HCl}$ and $0.1 \mathrm{M}$ $\mathrm{NaOH}$ were used to adjust the solution to the target $\mathrm{pH}$ at the start of the experiments. During the experiments, $2 \mathrm{~mL}$ samples were collected using a syringe at given time intervals and analyzed via high-performance liquid chromatography (HPLC). All degradation experiments were carried out at least in duplicate and the average values are presented.

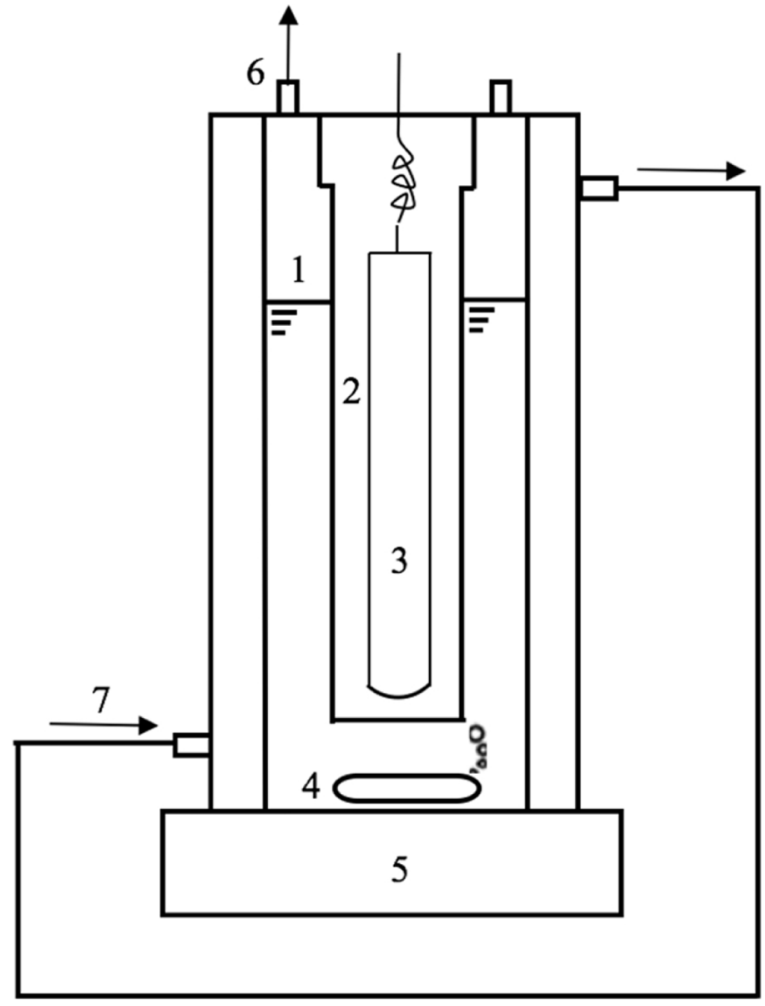

Fig. 1. Schematic diagram of the photo-reactor. 1-inner reactor, 2-quartz tube, 3-low pressure UV lamp, 4- magnetic bar, 5- magnetic bar stirrer, 6-sampling point, 7-cooling water recirculation system.

\subsection{Analytical methods}

The $\mathrm{pH}$ of the solution was determined with a $\mathrm{pH}$ meter (Mettler Toledo, Zaventem, Belgium). The concentration of 2,4-DCP was determined using an Agilent 1100 HPLC system equipped with a G1312A binary pump, a G1316A thermostatted column compartment, a G1367A autosampler and a G1314A UV detector. The detector was set at a wavelength of $280 \mathrm{~nm}$. Separation was carried out on an Agilent Eclipse Plus C18 $\left(4.6 \mathrm{~mm} \times 100 \mathrm{~mm}, \mathrm{~d}_{\mathrm{p}}=3.5 \mu \mathrm{m}\right)$ column at a flow rate of $1.0 \mathrm{~mL} / \mathrm{min}$, and the column temperature was maintained at $30^{\circ} \mathrm{C}$ using the thermostatted column compartment. The mobile phase consisted of $60 \% / 40 \%(\mathrm{v} / \mathrm{v}) \mathrm{MeOH}: \mathrm{H}_{2} \mathrm{O}$. The samples were analyzed immediately after being taken from the reactor, and without scavenging residual sulphite ions, since 2,4-DCP degradation was negligible in sulphite solution (less than $5 \%$ was degraded by $\mathrm{SO}_{3}{ }^{2-}$ in $48 \mathrm{~h}$ ).

The Box-Behnken Design (BBD) model is one of the most common design methods and is often considered to be efficient in estimating second-order quadratic polynomial equation and optimizing the process variables within the region of the three-dimensional observation space $[32,33]$. Experimental data designed by BBD were analyzed by response surface regression (RSREG) to fit the second-order quadratic polynomial model (Eq. (4)).

$\mathrm{Y}=\beta_{0}+\sum_{i=1}^{k} \beta_{i} X_{i}+\sum_{i=1}^{k} \beta_{i i} X_{i i}^{2}+\sum_{i=1}^{k} \sum_{j=1}^{k} \beta_{i j} X_{i} X_{j}$

With Y the predicted response (\% degradation efficiency of 2,4-DCP); $\mathrm{X}_{\mathrm{i}}, \mathrm{X}_{\mathrm{j}}$ independent variables (solution $\mathrm{pH}$, sulphite dosage, initial 2,4DCP concentration, UV intensity); $\beta_{0}$ the constant coefficient; $\beta_{i}$ the linear-term coefficient and $\beta_{\mathrm{ii}}$ the quadratic coefficient that refer to the influence of the single variable $i$ on the response; and $\beta_{i j}$ the cross coefficient, which determines the interaction effects between independent variables [34]. This equation will be used to predict the optimum levels of key process variables and the effect of their 


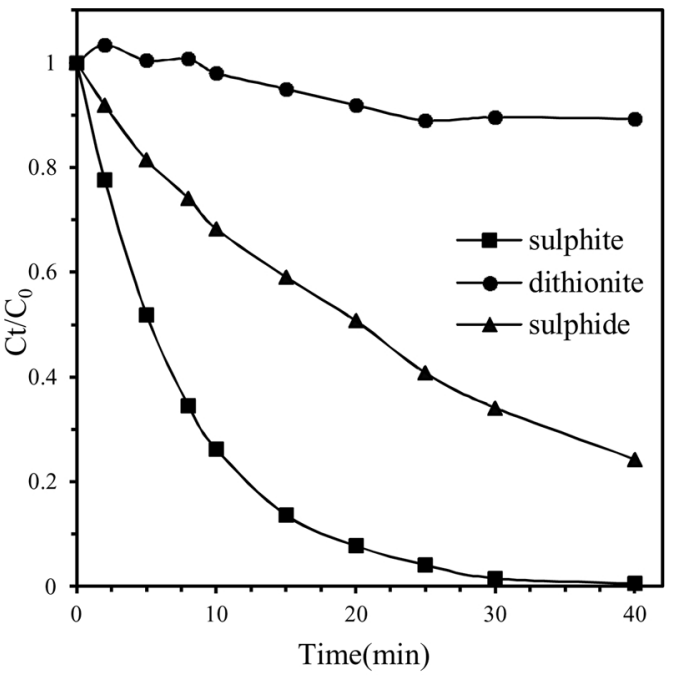

(a)

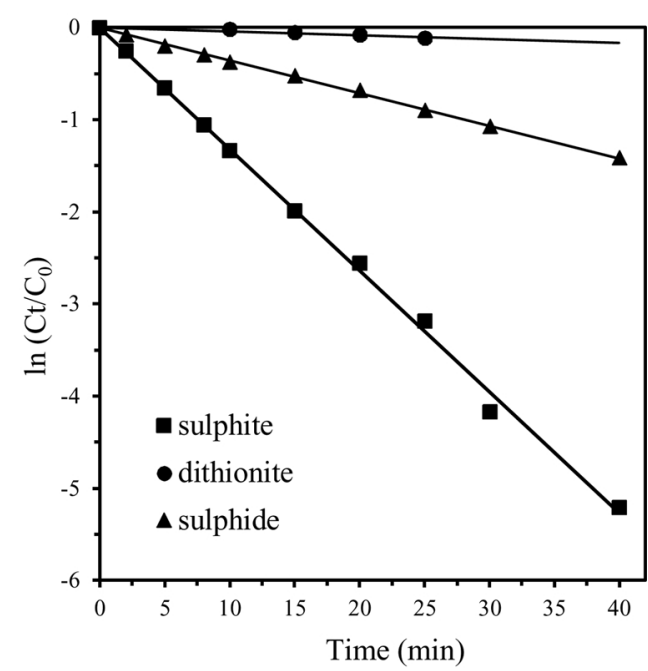

(b)

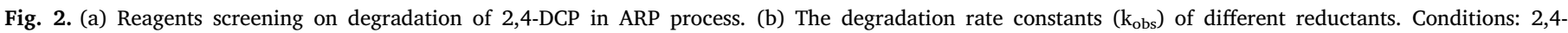
$\mathrm{DCP}=0.6 \mathrm{mM}, \mathrm{Na}_{2} \mathrm{SO}_{3}=\mathrm{Na}_{2} \mathrm{~S}_{2} \mathrm{O}_{4}=\mathrm{Na}_{2} \mathrm{~S}=8 \mathrm{mM}, \mathrm{I}_{0}=3260 \mu \mathrm{W} / \mathrm{cm}^{2}$.

interactions for 2,4-DCP removal.

\section{Results and discussion}

\subsection{Type of reductive agent}

A series of screening experiments were conducted to compare the effects of sulphite, dithionite and sulphide as reductive agents. The results are depicted in Fig. 2(a). The highest degradation efficiency for 2,4-DCP, i.e., $99.45 \%$ degradation after $40 \mathrm{~min}$ reaction time, was obtained for sulphite. Using sulphide and dithionite as reducing agents resulted in a much lower removal efficiency, which approached $75.71 \%$ and $10.73 \%$ after $40 \mathrm{~min}$ reaction time, respectively. The degradation of 2,4-DCP under sulphite/UV ARP follows a total second-order reaction with a first order relationship with both the concentrations of 2,4DCP and of the relevant reductive radicals. However, because the reductant is present in great excess, the concentration of the reductive radicals can be considered as constant throughout the reaction. As a result, a pseudo first-order kinetic model can be proposed to fit the experimental data All degradations follow pseudo first-order reaction kinetics, as described in Eq. (5).

$\frac{\mathrm{dC}_{2,4-\mathrm{DCP}}}{\mathrm{dt}}=-\mathrm{k}_{\mathrm{obs}} \times \mathrm{C}_{2,4-\mathrm{DCP}}$

With $\mathrm{C}_{2,4-\mathrm{DCP}}$ the 2,4-DCP concentration measured at irradiation time $t$ and $k_{\text {obs }}$ the observed pseudo first-order rate constant $\left(\mathrm{min}^{-1}\right)$ calculated as the slope of fitted linear regression. The results shown in Fig. 2(b) demonstrate that the highest reaction rate was obtained when using sulphite as reducing agent, resulting in a $\mathrm{k}_{\mathrm{obs}}=0.13 \mathrm{~min}^{-1}$, while the $\mathrm{k}_{\text {obs }}$ for dithionite and sulphide were $0.0041 \mathrm{~min}^{-1}$ and $0.036 \mathrm{~min}^{-1}$, respectively.

The difference in degradation efficiency between the reductants can be explained by the production of reactive radicals with different reductive capabilities [20]. Dithionite consists of a structure with a long and weak $\mathrm{S}-\mathrm{S}$ bond, which can easily be broken into two sulphur dioxide radical anions $\left(\mathrm{SO}_{2} \cdot{ }^{-}\right)$with a standard reduction potential $\left(\mathrm{E}_{0}\right)$ of $-0.66 \mathrm{~V}$ [35]. The maximum absorption peak is obtained at a wavelength of $315 \mathrm{~nm}$, which is optimal to break the S-S bond to yield radicals [21,36]. At the experimental wavelength of $253.7 \mathrm{~nm}$ employed in this study, the formation of $\mathrm{SO}_{2} \cdot{ }^{-}$will, however, not be optimal, resulting in a lower degradation efficiency of 2,4-DCP. Sulphide also absorbs UV, leading to the generation of reactive HS. ${ }^{-}$ions
$\left(\mathrm{E}_{0}=-0.45 \mathrm{~V}\right)$, but maximum absorption is obtained at a wavelength of $230 \mathrm{~nm}[37,38]$. Hence the experimental conditions used in this study are again not optimal for the formation of reactive ions originating from sulphide. It has been suggested that $\mathrm{e}_{\mathrm{aq}}{ }^{-}$and $\mathrm{SO}_{3} \cdot{ }^{-}$, formed by sulphite under UV irradiation with a wavelength of $254 \mathrm{~nm}$ [30,31], are very strong reductive species with a reduction potential of $-2.9 \mathrm{~V}$ [39] and $-0.73 \mathrm{~V}$ [40], respectively. Liu and Li, for example, demonstrated that the high degradation rate and dechlorination efficiency of vinyl chloride (VC) and monochloroacetic acid (MCAA) via the sulphite/UV process were due to the highly reductive capability of $\mathrm{e}_{\mathrm{aq}}{ }^{-}$and $\mathrm{SO}_{3} \cdot{ }^{-}[22,41]$. Because sulphite was seen to be the most effective reductive agent, this compound was further used in this study for the parameter evaluation.

\subsection{Effect of $p H$ on the degradation of 2,4-DCP by sulphite/UV ARP}

Fig. 3(a) depicts the effect of $\mathrm{pH}$ on the degradation of 2,4-DCP in the sulphite/UV process. By increasing the $\mathrm{pH}$ from 3.0 to 7.0 , a change in degradation efficiency was observed from $22.63 \%$ to $67.31 \%$ after $40 \mathrm{~min}$ reaction time. This trend was even intensified when further increasing the $\mathrm{pH}$, resulting in the total removal of 2,4-DCP after $40 \mathrm{~min}$ at a $\mathrm{pH}$ of 9 . At a $\mathrm{pH}$ of 10 , the highest removal rate was observed with a complete removal of 2,4-DCP after 20 min already. These observations were further quantified via the correlation between $\mathrm{k}_{\mathrm{obs}}$ and $\mathrm{pH}$, as shown in Fig. 3(b). When the initial $\mathrm{pH}$ of the reaction mixture increased from 3.0 to 7.0, a linear increase in $\mathrm{k}_{\mathrm{obs}}$ was observed from $0.0071 \mathrm{~min}^{-1}$ to $0.030 \mathrm{~min}^{-1}$, following a linear trend with a slope of 0.0057. A further increase in $\mathrm{pH}$ to 10.0 resulted in a considerably higher increase in $\mathrm{k}_{\mathrm{obs}}$, again linearly increasing with increasing $\mathrm{pH}$, but in this region with a slope of 0.0624 . This observation is explained by the $\mathrm{pH}$ dependency of the distribution ratio of sulfur species [20,22], which was calculated by Visual MINTEQ 3.1 and is illustrated in Fig. 4. At lower $\mathrm{pH}$, the bisulphite ion $\left(\mathrm{HSO}_{3}{ }^{-}\right.$) and metabisulphite ion $\left(\mathrm{S}_{2} \mathrm{O}_{5}{ }^{2-}\right)$ are predominantly present, together contributing for $83.75 \%$ to the sulphur species in the mixture. It was reported by Hayon et al. $[42,43]$ that $\mathrm{HSO}_{3}{ }^{-}$only absorbs little UV-light without forming any transient radicals, and hence no reductive radicals, required for 2,4DCP degradation, are generated. The $\mathrm{S}_{2} \mathrm{O}_{5}{ }^{2-}$ ion is reported to be susceptible to UV decomposition, with the formation of sulphite radicals and sulphur dioxide. Even though these radicals could contribute to the degradation of 2,4-DCP, the fraction of $\mathrm{S}_{2} \mathrm{O}_{5}{ }^{2-}$ ions was limited (maximum $15 \%$ of $0.8 \mathrm{mM}$ sulphite, $\mathrm{pH}=4.4$ ) and as a result, only 


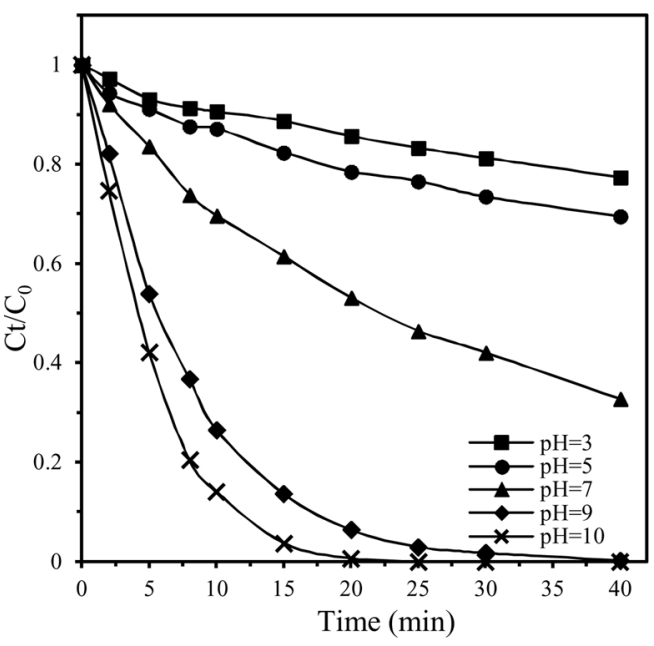

(a)

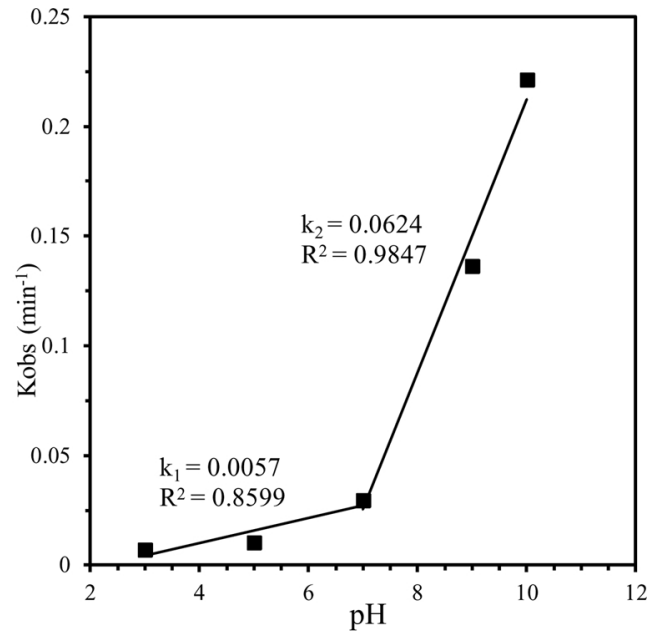

(b)

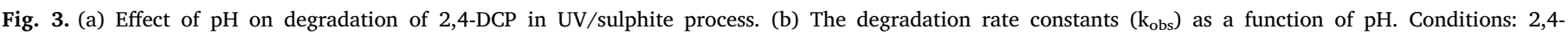
$\mathrm{DCP}=0.6 \mathrm{mM}, \mathrm{S}(\mathrm{IV})=8 \mathrm{mM}, \mathrm{I}_{0}=3260 \mu \mathrm{W} / \mathrm{cm}^{2}$.

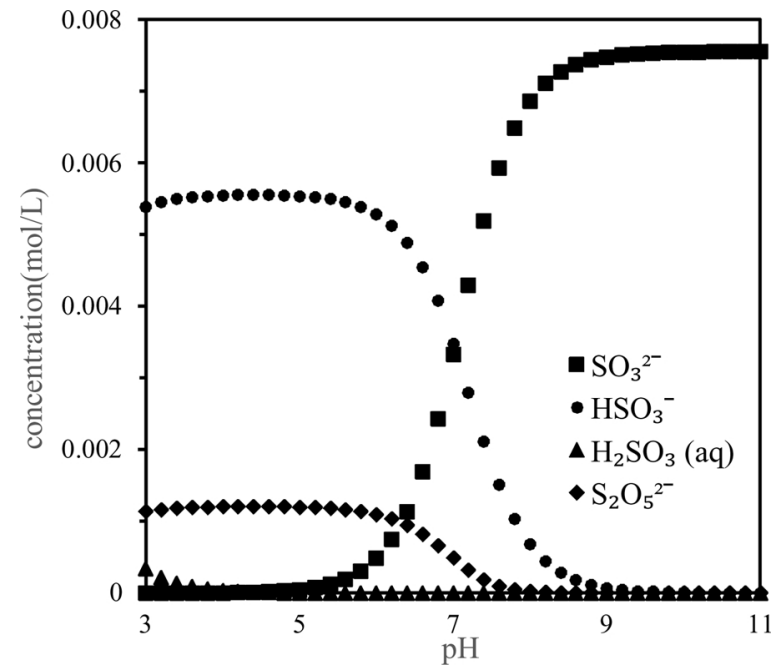

Fig. 4. Distribution of sulfur species in $0.8 \mathrm{mM}$ sulphite at $\mathrm{pH}$ from 3.0 to 11.0.

slow 2,4-DCP degradation was observed under these acidic conditions. However, the sulphite ion $\left(\mathrm{SO}_{3}{ }^{2-}\right)$ dominates at a $\mathrm{pH}$ higher than its $\mathrm{pK}_{\mathrm{a}}$ value (7.2), and almost $93.75 \%$ of the total sulphur species are present in the form of sulphite when the $\mathrm{pH}$ reaches 10.0. As already discussed in Section 3.1, $\mathrm{SO}_{3}{ }^{2-}$ results in the generation of $\mathrm{e}_{\mathrm{aq}}{ }^{-}$and $\mathrm{SO}_{3} \cdot{ }^{-}$, which are regarded as the most effective reductive radicals for 2,4-DCP reduction. Consequently, increasing the $\mathrm{pH}$ gives rise to an elevated production of $\mathrm{e}_{\mathrm{aq}}{ }^{-}$and $\mathrm{SO}_{3} \cdot{ }^{-}$, hence leading to a higher 2,4DCP degradation.

\subsection{Effect of sulphite dose}

The effect of sulphite concentration on the removal of 2,4-DCP is depicted in Fig. 5(a). Increasing the sulphite concentration from $1 \mathrm{mM}$ to $16 \mathrm{mM}$ resulted in a higher degradation efficiency of 2,4-DCP, increasing from $32.17 \%$ to $99.37 \%$ for a 40 min reaction time. The correlation between the reaction rate constant and sulphite dose is presented in Fig. 5(b). Two degradation pathways were suggested by Botlaguduru [23]: (i) direct photolysis and (ii) a radical-reaction mechanism, which both contribute to the reduction of the target pollutant. Direct photolysis takes place when the pollutant absorbs photons under UV irradiation, is hence transformed to an excited state, and decomposed subsequently [44]. Different compounds in different states of protonation may have different absorption properties [45]. The molar absorption coefficient $\left(\varepsilon, \mathrm{M}^{-1} \mathrm{~cm}^{-1}\right)$ and quantum yield $(\varphi$, mol Einstein ${ }^{-1}$ ) are two key factors that determine the direct photolysis rate at a certain wavelength. In this study, the $\varepsilon$ value $\left(\varepsilon=232 \mathrm{M}^{-1} \mathrm{~cm}^{-1}\right)$ and the $\varphi$ value $\left(\varphi=0.032 \mathrm{~mol} \mathrm{Einstein}^{-1}\right)$ for 2,4-DCP were relatively low at a wavelength of $254 \mathrm{~nm}$, resulting in a weak reactivity of 2,4-DCP to photo-excitation by UV-light. It can be concluded from the results that only $14.91 \%$ of 2,4 -DCP was degraded at a reaction time of $40 \mathrm{~min}$ under sole UV irradiation (as illustrated in Fig. 5(a) for $0 \mathrm{mM}$ sulphite), indicating that direct photolysis is not the main mechanism for 2,4-DCP degradation. Additionally, if direct photolysis would dominate the degradation mechanism, a higher sulphite dosage would lead to a decrease in the average light intensity to be absorbed by 2,4-DCP, thereby reducing the $\mathrm{k}_{\text {obs }}[23,39]$. The obtained experimental results (as shown in Fig. 5(b)) suggest on the contrary a positive trend, which confirms that the dominant mechanism of 2,4DCP reduction is the reaction with reductive radicals generated from sulphite under UV irradiation and is in agreement with the previous discussion in Sections 3.1 and 3.2. A considerable increase in $\mathrm{k}_{\mathrm{obs}}$ from 0.053 to $0.14 \mathrm{~min}^{-1}$ was observed when the sulphite dosage was increased from 1 to $5 \mathrm{mM}$. However, further increasing the initial sulphite concentration to $16 \mathrm{mM}$ only resulted in a limited further increase of $\mathrm{k}_{\mathrm{obs}}$ to $0.145 \mathrm{~min}^{-1}$. The initial increase in sulphite concentration resulted in a higher removal efficiency with a proportional increase in $\mathrm{k}_{\mathrm{obs}}$, due to a higher absorbance of incident light by sulphite and a higher production of radicals responsible for the degradation $[46,47]$. At higher radical concentration, however, the produced radicals start reacting with each other and with the intermediates that are produced during the process (now acting as scavengers), leading to a larger consumption of radicals and hence explains the inhibition of the proportional increase of degradation rate constant [24,39].

\subsection{Effect of initial 2,4-DCP concentration}

Fig. 6 shows the influence of the initial 2,4-DCP concentration on 2,4-DCP degradation kinetics in the UV/sulphite process. Increasing the concentration of 2,4-DCP results in a decrease of $\mathrm{k}_{\text {obs. }}$. This is in agreement with a previous study by Liu et al. [41], in which a simplified kinetic model was proposed to calculate the effect of initial 2,4DCP concentration on $\mathrm{k}_{\mathrm{obs}}$. As illustrated in Eqs. (6)-(8), the first step of this model is the photolysis of sulphite under UV light to generate reductive radicals ( $\mathrm{R}: \mathrm{e}_{\mathrm{aq}}{ }^{-}$and $\mathrm{SO}_{3} \cdot{ }^{-}$). The second and third steps are 


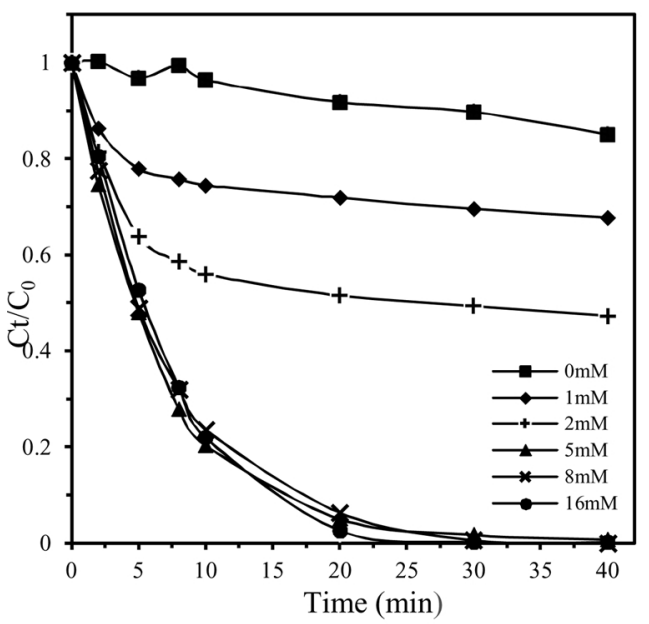

(a)

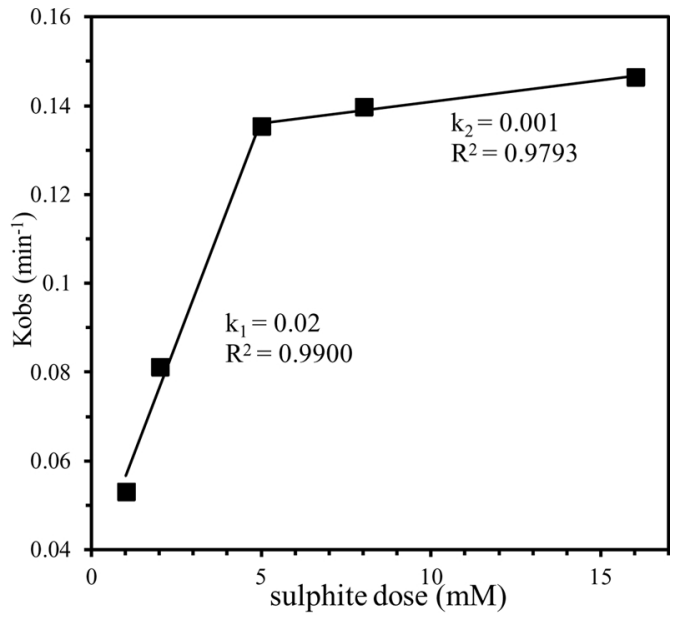

(b)

Fig. 5. (a) Effect of sulphite concentration on degradation of 2,4-DCP in UV/sulphite process. (b) The degradation rate constants ( $\mathrm{k}_{\mathrm{obs}}$ ) as a function of sulphite dose. Conditions: $\mathrm{pH}=8.5,2,4-\mathrm{DCP}=0.6 \mathrm{mM}, \mathrm{I}_{0}=3260 \mu \mathrm{W} / \mathrm{cm}^{2}$.

the reactions of these radicals with the target compound (2,4-DCP) and intermediate products ( $\mathrm{S}$ : scavengers during the process). In these equations, $\mathrm{k}_{1}$ was a constant related to the quantum yield of the sulphite $\left(\varphi_{\text {sulphite }}\right)$, the molar absorptivity of sulphite $\left(\varepsilon_{\text {lnsulphite }}\right)$, and the UV light intensity $\left(\mathrm{I}_{0}\right) . \mathrm{k}_{2}$ and $\mathrm{k}_{3}$ are the second order rate constants of the reactions of reductive species with 2,4-DCP and S, respectively $[20,41]$.

sulphite + ho $\rightarrow \mathrm{R}, \quad \mathrm{r}_{1}=\mathrm{k}_{1} \cdot \mathrm{C}_{\text {sulphite }}\left(\mathrm{k}_{1}=\varphi_{\text {sulphite }} \cdot \varepsilon_{\text {lnsulphite }} \cdot \mathrm{I}_{0}\right)$

$2,4-\mathrm{DCP}+\mathrm{R} \rightarrow \mathrm{P}_{1}+\mathrm{S}, \quad \mathrm{r}_{2}=\mathrm{k}_{2} \cdot \mathrm{C}_{2,4-\mathrm{DCP}} \cdot \mathrm{C}_{\mathrm{R}}$

$\mathrm{S}+\mathrm{R} \rightarrow \mathrm{P}_{2}, \quad \mathrm{r}_{3}=\mathrm{k}_{3} \cdot \mathrm{C}_{\mathrm{s}} \cdot \mathrm{C}_{\mathrm{R}}$

It was assumed that in stationary situations, the consumption of radicals is equal to the production of radicals $\left(\mathrm{dC}_{\mathrm{R}} /\right.$ $\mathrm{dt}=\mathrm{r}_{1}-\mathrm{r}_{2}-\mathrm{r}_{3}=0$ ), because the reaction was fast and the time derivative of the concentration of the reductive species was negligible. Based on these individual steps, an overall reaction rate equation was derived, which is presented in Eq. (9). The accompanying expression for the reaction rate constant is shown in Eq. (10).

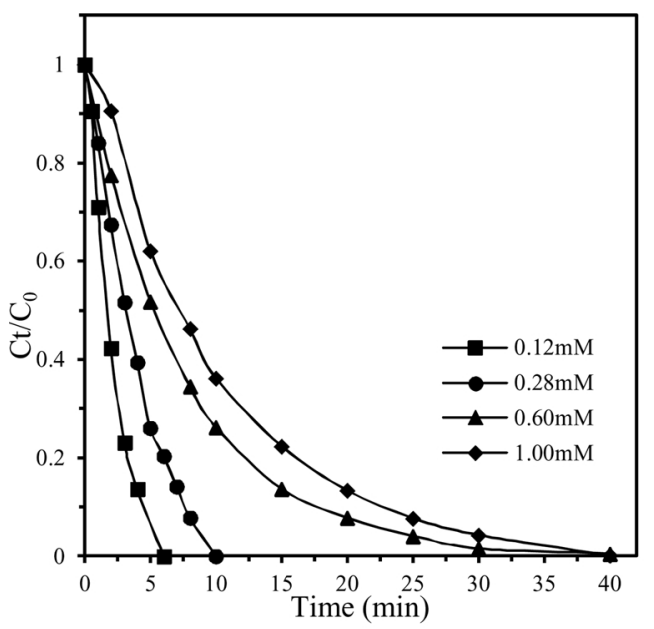

(a)

$$
\begin{aligned}
& \frac{\mathrm{dC}_{2,4-\mathrm{DCP}}}{\mathrm{dt}}=-\mathrm{r}_{2}=-\mathrm{k}_{\mathrm{obs}} \times \mathrm{C}_{2,4-\mathrm{DCP}} \\
& \mathrm{k}_{\mathrm{obs}}=\frac{\mathrm{k}_{1} \mathrm{k}_{2} \mathrm{C}_{\text {sulphite }}}{\mathrm{k}_{2} \mathrm{C}_{2,4-\mathrm{DCP}}+\mathrm{k}_{3} \mathrm{C}_{\mathrm{s}}}
\end{aligned}
$$

Following the latter equation, it is evident that the degradation rate will decrease as the actual 2,4-DCP concentration increases and the amount of intermediate products $\left(\mathrm{C}_{\mathrm{s}}\right)$ was not excessively high. This was consistent with the experimental results (shown in Fig. 6(b)) wherein $\mathrm{k}_{\mathrm{obs}}$ decreased from 0.48 to $0.10 \mathrm{~min}^{-1}$.

\subsection{Effect of UV intensity}

To evaluate the effect of UV light intensity on 2,4-DCP degradation, low-pressure UV lamps were applied with a power output of $5 \mathrm{~W}, 11 \mathrm{~W}$ and $18 \mathrm{~W}$. As illustrated in Fig. 7(a), it was observed that the sole application of sulphite did not result in a significant degradation of 2,4DCP in the absence of UV, whereas the combined sulphite/UV system yielded high degradation efficiencies. The degradation rate was linearly correlated to the UV light intensity, as demonstrated by the linear

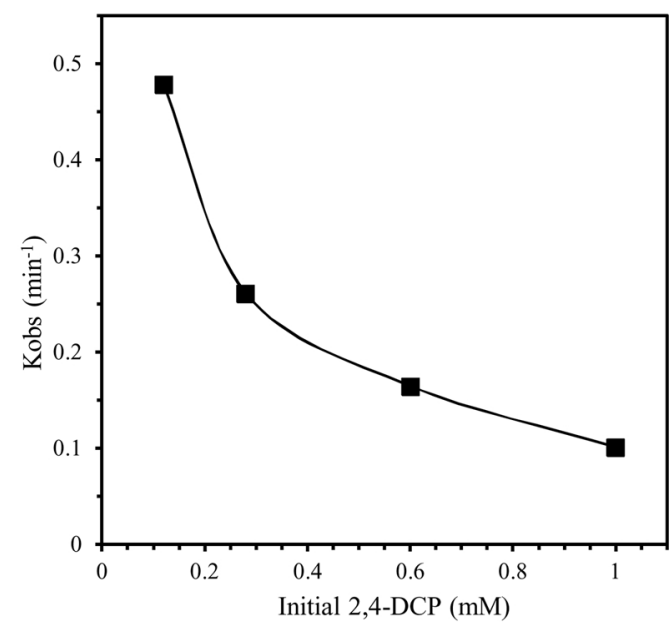

(b)

Fig. 6. (a) Effect of initial 2,4-DCP concentration on degradation of 2,4-DCP in UV/sulphiteprocess. (b) The degradation rate constants ( $\mathrm{k}_{\mathrm{obs}}$ ) as a function of initial $2,4-\mathrm{DCP}$ concentration. Conditions: $\mathrm{pH}=8.5, \mathrm{~S}$ (IV) $=8 \mathrm{mM}$, I0 $=3260 \mu \mathrm{W} / \mathrm{cm}^{2}$. 


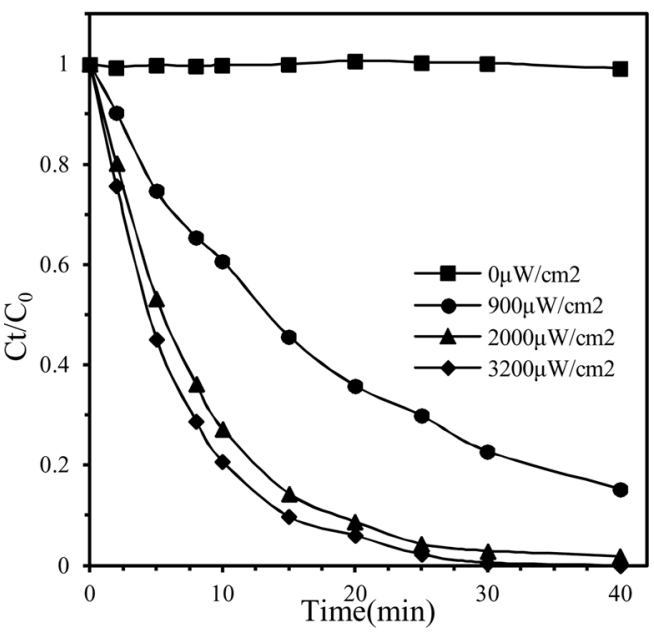

(a)

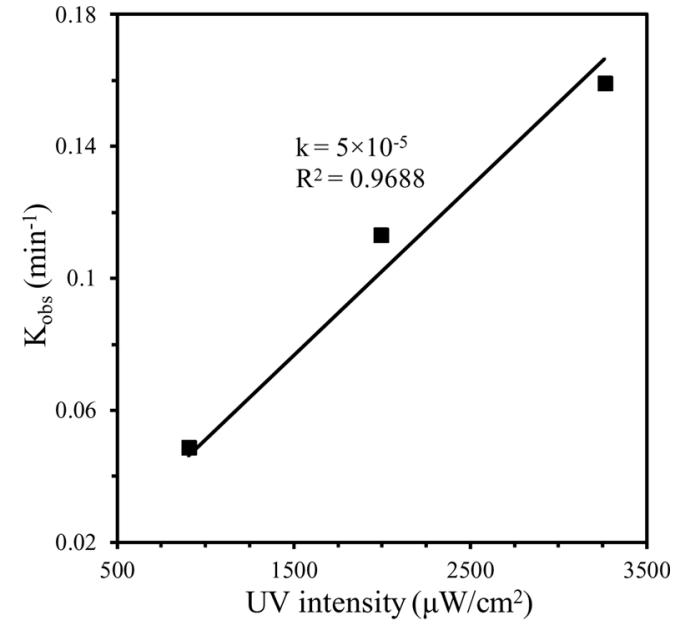

(b)

Fig. 7. (a) Effect of UV intensity on degradation of 2,4-DCP in UV/sulphite process. (b) The degradation rate constants ( $\mathrm{k}_{\mathrm{obs}}$ ) as a function of UV intensity. Conditions: $\mathrm{pH}=8.5, \mathrm{~S}(\mathrm{IV})=8 \mathrm{mM}, 2,4-\mathrm{DCP}=0.6 \mathrm{mM}$.

increase in reaction rate constants (shown in Fig. $7(\mathrm{~b})$ ), from $0.049 \mathrm{~min}^{-1}$ to $0.16 \mathrm{~min}^{-1}$ with a $\mathrm{R}^{2}$ of 0.968 ). According to previous studies of Botlaguduru et al. [23] and Liu et al. [41], more reductive species are produced as more energy is introduced into the system (which can be absorbed by the reductants). Hence, higher UV irradiance improves the degradability of the pollutant.

\subsection{Statistical modelling for degradation process optimization}

A Box-Behnken model with four factors was chosen to elucidate the interactions between the selected factors and to optimize the key process parameters for enhanced 2,4-DCP degradation. A multiple regression analysis, neglecting insignificant terms was used to fit the data and the following second-order quadratic polynomial equation was derived:

$\mathrm{Y}=22.79+47.02 \mathrm{X}_{1}+37.57 \mathrm{X}_{2}-23.52 \mathrm{X}_{3}+39.85 \mathrm{X}_{4}-16.66 \mathrm{X}_{2} \mathrm{X}_{3}$

$+20.99 \mathrm{X}_{1}^{2}-32.99 \mathrm{X}_{2}^{2}+16.24 \mathrm{X}_{3}^{2}-22.14 \mathrm{X}_{4}^{2}$

where $Y$ represents the degradation efficiency for a 10 min reaction time and $\mathrm{X}_{1}, \mathrm{X}_{2}, \mathrm{X}_{3}, \mathrm{X}_{4}$ are the values of solution $\mathrm{pH}$, sulphite dosage, initial 2,4-DCP concentration and UV intensity, respectively.

An analysis of variance (ANOVA) was performed to evaluate the significance of the fit of the mathematical model in view of the experimental results (shown in Table 1). The "F-value" of this model is 20.56, and the value of "Prob $>F$ " is less than 0.0001, implying that the model was highly significant and only $0.01 \%$ of the total variation could not be explained by the model due to the noise. All the linear $\left(\mathrm{X}_{1}\right.$, $\left.\mathrm{X}_{2}, \mathrm{X}_{3}, \mathrm{X}_{4}\right)$ and quadratic $\left(\mathrm{X}_{2}^{2}, \mathrm{X}_{4}^{2}\right)$ terms of this model were significant, while the interaction term $\mathrm{X}_{2} \mathrm{X}_{3}$ and the quadratic terms $\mathrm{X}_{1}{ }^{2}$ and $\mathrm{X}_{3}{ }^{2}$ were less significant, since the "p-value" of these terms was higher than 0.05 . The coefficient of determination $\left(R^{2}\right)$ defined as the ratio of the explained variation versus the total variation [48], was calculated as 0.934 indicating that only $6.57 \%$ of the total variables for $2,4-\mathrm{DCP}$ degradation could not be explained by the model. The adjusted $\mathrm{R}^{2}$ is a modified value of $\mathrm{R}^{2}$, adjusted to the number of predictors in the model. It only increases when significant variables are added to the model and will decrease with the addition of non-significant variables. $\mathrm{R}^{2}$, on the other hand, will continuously increase, regardless of the significance of input variables [34]. It is hence desirable to have a small difference between adjusted $R^{2}$ and $R^{2}$ to judge the fitness of the model. As presented in Table 1 , the value of the adjusted $R^{2}$ is calculated as 0.889 meaning that only $4.54 \%$ of the total variation in the model is due to
Table 1

Analysis of variance (ANOVA) for 2,4-DCP degradation efficiency.

\begin{tabular}{llllll}
\hline Source & Sum of Squares & Df & Mean Square & F Value & p-value Prob $>$ F \\
\hline Model & 23289.34 & 9 & 2587.70 & 20.56 & $<0.0001$ \\
$\mathrm{X}_{1}$ & 7378.16 & 1 & 7378.16 & 58.61 & $<0.0001$ \\
$\mathrm{X}_{2}$ & 4919.94 & 1 & 4919.94 & 39.08 & $<0.0001$ \\
$\mathrm{X}_{3}$ & 1678.08 & 1 & 1678.08 & 13.33 & 0.0029 \\
$\mathrm{X}_{4}$ & 4425.75 & 1 & 4425.75 & 35.16 & $<0.0001$ \\
$\mathrm{X}_{1}{ }^{2}$ & 362.47 & 1 & 362.47 & 2.88 & 0.1135 \\
$\mathrm{X}_{2}{ }^{2}$ & 2728.58 & 1 & 2728.58 & 21.67 & 0.0004 \\
$\mathrm{X}_{3}{ }^{2}$ & 590.35 & 1 & 590.35 & 4.69 & 0.0495 \\
$\mathrm{X}_{4}{ }^{2}$ & 791.36 & 1 & 791.36 & 6.29 & 0.0262 \\
$\mathrm{X}_{2} \mathrm{X}_{3}$ & 451.22 & 1 & 451.22 & 3.58 & 0.0808 \\
Residual & 1636.58 & 13 & 125.89 & & \\
Cor Total & 24925.91 & 22 & & & \\
Std.Dev. & 11.22 & \multicolumn{5}{c}{ R-Squared } & 0.9343 & \\
Mean & 49.42 & \multicolumn{5}{c}{ Adj R-Squared } & 0.8889 & \\
C.V.\% & 22.70 & \multicolumn{5}{c}{ Aded R-Squared } & 0.7607 & \\
PRESS & 5965.48 & \multicolumn{5}{c}{ Precisior } & 14.474 & \\
& & & & & \\
\hline
\end{tabular}

non-significant variables, suggesting an unbiased estimate of the number of variables. Moreover, the predicted $\mathrm{R}^{2}$ of 0.76 was in reasonable agreement with the adjusted $\mathrm{R}^{2}$ of 0.89 , with a difference of only 0.13 , indicating that the model is able to sufficiently explain the studied experimental range and the model is not too complicated. The experimental results versus predicted values by the model are shown in Fig. 8(a). Almost all of the points approach the straight line $(y=x)$ in the middle of the figure, which confirms that the model is reliable to predict 2,4-DCP degradation in this study. Additionally, the residual plots of the model were distributed randomly without any trends (as illustrated in Fig. 8(b)), which indicated a good prediction of the maximum response along with constant variance and adequacy of the quadratic models [49].

The adequate precision of the model measures the range in predicted response and its associated error (i.e., the signal to noise ratio), and is desirably higher than 4 [50]. In this study, its value was 14.47, indicating that the model was accurate and could be used to predict the response. Furthermore, the coefficient of variation (CV) presents the reliability of the model, expressed as the percent ratio between the standard error of the estimate and the mean value of the observed response [34], The observed value of $22.70 \%$ indicated that the model was reliable and precise. 


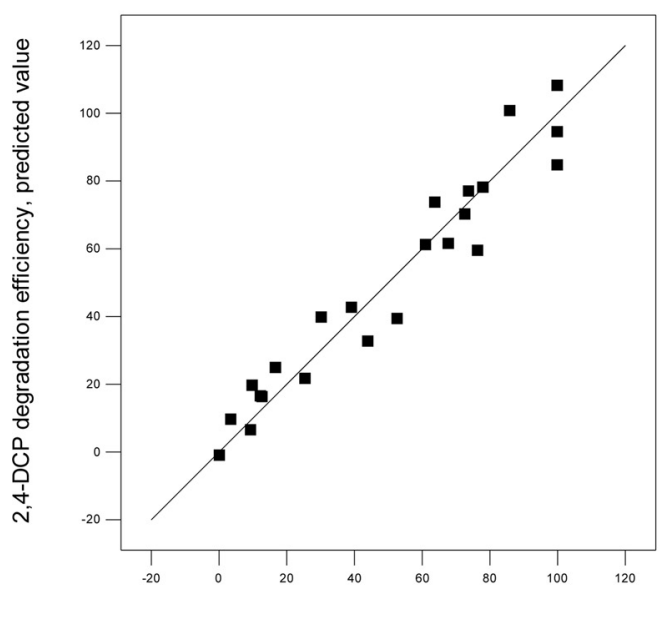

2,4-DCP degradation efficiency, experimental value

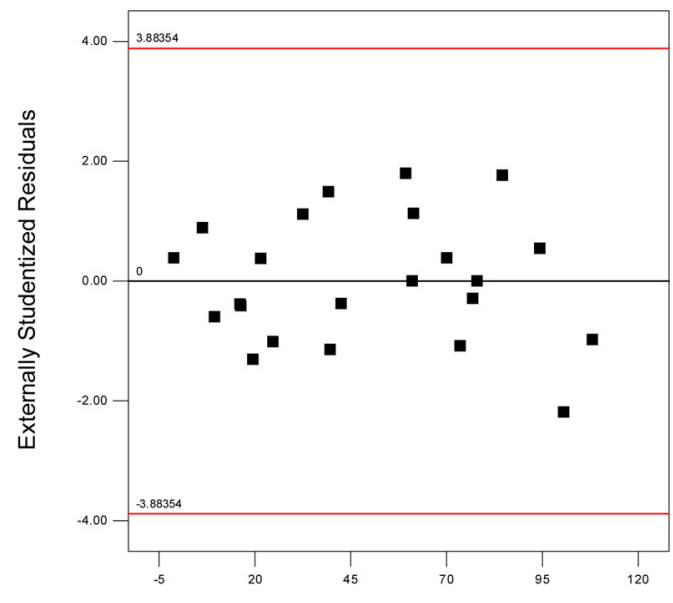

2,4-DCP degradation efficiency, predicted value

(a)

(b)

Fig. 8. (a) Predicted versus experimental value of 2,4-DCP degradation efficiency. (b) Residual plot of quadratic model for 2,4-DCP degradation efficiency.

\section{Conclusion}

This study demonstrated the ability of UV-based ARP with dithionate, sulphide and sulphite as reductive agents to degrade 2,4-DCP. The efficiency of the different reductive agents depended on the production of reactive radicals with different reductive ability. Compared to $\mathrm{SO}_{2} \cdot{ }^{-}$ and $\mathrm{HS} \cdot{ }^{-}, \mathrm{e}_{\mathrm{aq}}{ }^{-}$and $\mathrm{SO}_{3} \cdot{ }^{-}$generated by UV-irradiated sulphite, exhibited the highest reductive capability, and as a result, sulphite was selected as the best reductive agent. The degradation of 2,4-DCP via sulphite/UV generally followed pseudo first-order reaction kinetics. Increasing the $\mathrm{pH}$ had a limited influence on the 2,4-DCP reduction up to a $\mathrm{pH}$ of 7 , but was considerably higher for alkaline conditions because $\mathrm{SO}_{3}{ }^{2-}$ was the dominant sulphur species at higher $\mathrm{pH}$. Increasing the sulphite dose had a significant positive influence on the degradation kinetics, as well as the intensity of the UV light. On the contrary, increasing the initial 2,4-DCP concentration had a negative impact on the degradation kinetics. A quadratic polynomial equation was selected as statistical model and calculated by Box-Behnken Design, which proved to be precise and reliable to describe the significance of different parameters as well as predicting the degradation process of 2,4-DCP. Solution $\mathrm{pH}$, sulphite dose and UV intensity were identified to be key process variables as evaluated by ANOVA. The coefficient of determination implied that the experimental results were in reasonable agreement with the predicted values. In conclusion, this study proposed a promising method of applying UV-based ARP on degradation of 2,4DCP in a water treatment system. The approach can efficiently degrade 2,4-DCP with high degradation kinetics, when key process variables, solution $\mathrm{pH}$, sulphite dose and light intensity are optimized.

\section{Acknowledgement}

This work was supported by the China Scholarship Council (CSC) [grant number 201606200054].

\section{References}

[1] Akin Karci, Degradation of chlorophenols and alkylphenol ethoxylates, two representative textile chemicals, in water by advanced oxidation processes: the state of the art on transformation products and toxicity, Chemosphere 99 (2014) 1-18.

[2] A. Karci, I. Arslan-Alaton, T. Olmez-Hanci, M. Bekbölet, Transformation of 2,4-dichlorophenol by $\mathrm{H}_{2} \mathrm{O}_{2}$ /UV-C, Fenton and photo-Fenton processes: oxidation products and toxicity evolution, J. Photochem. Photobiol. A: Chem. 230 (2012) 65-73.

[3] M. Czaplicka, Sources and transformations of chlorophenols in the natural environment, Sci. Total Environ. 322 (2004) 21-39.

[4] M. Pera-Titus, V. García-Molina, M.A. Baños, J. Giménez, S. Esplugas, Degradation of chlorophenols by means of advanced oxidation processes: a general review, Appl. Catal. B: Environ. 47 (2004) 219-256.

[5] P. Wu, G.P. Yang, X.K. Zhao, Sorption behavior of 2,4-dichlorophenol on marine sediment, J. Colloid Interface Sci. 265 (2003) 251-256.

[6] J. Gamage McEvoy, W. Cui, Z. Zhang, Synthesis and characterization of Ag/AgClactivated carbon composites for enhanced visible light photocatalysis, Appl. Catal. B: Environ. 144 (2014) 702-712.

[7] W. Zhou, M. Cao, N. Li, S. Su, X. Zhao, J. Wang, X. Li, C. Hu, Ag@AgHPW as a plasmonic catalyst for visible-light photocatalytic degradation of environmentally harmful organic pollutants, Mater. Res. Bull. 48 (2013) 2308-2316.

[8] Z. Liu, W. Xu, J. Fang, X. Xu, S. Wu, X. Zhu, Z. Chen, Decoration of BiOI quantum size nanoparticles with reduced graphene oxide in enhanced visible-light-driven photocatalytic studies, Appl. Surf. Sci. 259 (2012) 441-447.

[9] Y. Wang, K. Deng, L. Zhang, Visible light photocatalysis of BiOI and its photocatalytic activity enhancement by in situ ionic liquid modification, J. Phys. Chem. C 115 (2011) 14300-14308.

[10] D. Arsene, C. Catrinescu, B. Drăgoi, C. Teodosiu, Catalytic wet hydrogen peroxide oxidation of 4-chlorophenol over iron-exchanged clays, Environ. Eng. Manag. J. 9 (2010) 7-16.

[11] X. Li, M. Zhou, Y. Pan, L. Xu, Pre-magnetized $\mathrm{Fe}^{\circ}$ /persulfate for notably enhanced degradation and dechlorination of 2,4-dichlorophenol, Chem. Eng. J. 307 (2017) 1092-1104.

[12] Y. Cui, Z. Ding, P. Liu, M. Antonietti, X. Fu, X. Wang, Metal-free activation of $\mathrm{H}_{2} \mathrm{O}_{2}$ by $\mathrm{g}_{-} \mathrm{C}_{3} \mathrm{~N}_{4}$ under visible light irradiation for the degradation of organic pollutants, Phys. Chem. Chem. Phys. 14 (2012) 1455-1462.

[13] S. Adishkumar, S. Kanmani, Treatment of phenolic wastewaters in single baffle reactor by Solar $/ \mathrm{TiO}_{2} / \mathrm{H}_{2} \mathrm{O}_{2}$ process, Desalin. Water Treat. 24 (2010) 67-73.

[14] T. Olmez-Hanci, I. Arslan-Alaton, G. Basar, Multivariate analysis of anionic, cationic and nonionic textile surfactant degradation with the $\mathrm{H}_{2} \mathrm{O}_{2}$ /UV-C process by using the capabilities of response surface methodology, J. Hazard. Mater. 185 (2011) 193-203.

[15] I. Arslan-Alaton, N. Ayten, T. Olmez-Hanci, Photo-Fenton-like treatment of the commercially important $\mathrm{H}$-acid: process optimization by factorial design and effects of photocatalytic treatment on activated sludge inhibition, Appl. Catal. B: Environ. 96 (2010) 208-217.

[16] L. Rizzo, Bioassays as a tool for evaluating advanced oxidation processes in water and wastewater treatment, Water Res. 45 (2011) 4311-4340.

[17] M. Krebel, H. Kusic, N. Koprivanac, J. Meixner, A.L. Bozic, Treatment of chlorophenols by UV-based processes: correlation of oxidation by-products, wastewater parameters, and toxicity, J. Environ. Eng. 137 (2011) 639-649.

[18] I. Oller, S. Malato, J.A. Sánchez-Pérez, Combination of advanced oxidation processes and biological treatments for wastewater decontamination-a review, Sci. Total Environ. 409 (2011) 4141-4166.

[19] A. Karci, I. Arslan-Alaton, T. Olmez-Hanci, M. Bekbölet, Transformation of 2,4-dichlorophenol by $\mathrm{H}_{2} \mathrm{O}_{2} / \mathrm{UV}-\mathrm{C}$, Fenton and photo-Fenton processes: oxidation products and toxicity evolution, J. Photochem. Photobiol. A: Chem. 230 (2012) 65-73.

[20] X. Liu, B.P. Vellanki, B. Batchelor, A. Abdel-Wahab, Degradation of 1,2-dichloroethane with advanced reduction processes (ARPs): effects of process variables and mechanisms, Chem. Eng. J. 237 (2014) 300-307.

[21] X. Liu, S. Yoon, B. Batchelor, A. Abdel-Wahab, Photochemical degradation of vinyl chloride with an advanced reduction process (ARP) —effects of reagents and $\mathrm{pH}$, Chem. Eng. J. 215-216 (2013) 868-875. 
[22] X. Li, G. Liu, J. Fang, S. Yue, Y. Guan, L. Chen, X. Liu, Efficient reductive dechlorination of monochloroacetic acid by sulfite/UV process, Environ. Sci. Technol. 46 (2012) 7342-7349.

[23] V.S.V. Botlaguduru, B. Batchelor, A. Abdel-Wahab, Application of UV-sulfite advanced reduction process to bromate removal, J. Water Process Eng. 5 (2015) $76-82$.

[24] B. Jung, H. Farzaneh, A. Khodary, A. Abdel-Wahab, Photochemical degradation of trichloroethylene by sulfite-mediated UV irradiation, J. Environ. Chem. Eng. 3 (2015) 2194-2202.

[25] B. Jung, R. Nicola, B. Batchelor, A. Abdel-Wahab, Effect of low- and mediumpressure Hg UV irradiation on bromate removal in advanced reduction process, Chemosphere 117 (2014) 663-672.

[26] B.P. Vellanki, B. Batchelor, A. Abdel-Wahab, Advanced reduction processes: a new class of treatment processes, Environ. Eng. Sci. 30 (2013) 264-271.

[27] B.P. Vellanki, B. Batchelor, Perchlorate reduction by the sulfite/ultraviolet light advanced reduction process, J. Hazard. Mater. 262 (2013) 348-356.

[28] C.A. Linkous, C. Huang, J.R. Fowler, UV photochemical oxidation of aqueous sodium sulfide to produce hydrogen and sulfur, J. Photochem. Photobiol. A: Chem. 168 (2004) 153-160.

[29] J. Fu, Z.-M. Zhang, J.-Y. Tang, Q.-F. Zeng, S.-Q. An, H.-L. Zhu, Photoreduction of reactive brilliant red $\mathrm{X}-3 \mathrm{~B}$ by ultraviolet irradiation/potassium borohydride/sodium bisulfite, J. Environ. Eng. 136 (2010) 1314-1319.

[30] Y. Zuo, Y. Deng, Iron(II)-catalyzed photochemical decomposition of oxalic acid and generation of $\mathrm{H}_{2} \mathrm{O}_{2}$ in atmospheric liquid phases, Chemosphere 35 (1997) 2051-2058.

[31] M. Fischer, P. Warneck, Photodecomposition and Photooxidation of Hydrogen Sulfite in Aqueous Solution, (1996).

[32] G. Annadurai, S. Mathalai Balan, T. Murugesan, Box-Behnken design in the development of optimized complex medium for phenol degradation using Pseudomonas putida (NICM 2174), Bioprocess. Eng. 21 (1999) 415-421.

[33] J.H. Jo, D.S. Lee, D. Park, W.S. Choe, J.M. Park, Optimization of key process variables for enhanced hydrogen production by Enterobacter aerogenes using statistical methods, Bioresour. Technol. 99 (2008) 2061-2066.

[34] S. Nam, H. Cho, J. Han, N. Her, Photocatalytic degradation of acesulfame K : optimization using the Box-Behnken design (BBD), Process Saf. Environ. Prot. 113 (2017) $10-21$.

[35] S.G. Mayhew, The redox potential of dithionite and SO-2 from equilibrium reactions with flavodoxins, methyl viologen and hydrogen plus hydrogenase, Eur. J. Biochem. 85 (1978) 535-547.

[36] S.G. Pukhovskaya, L.Z. Guseva, S.V. Makarov, E.V. Naidenko, A new procedure for the spectrophotometric determination of nitrogen(II) oxide in solutions, J. Anal.
Chem. 60 (2005) 21-23.

[37] K.D.B. Dijkstra, J. Kipping, N. Mézière, Sixty new dragonfly and damselfly species from Africa (Odonata), Odonatologica 44 (2015) 447-678.

[38] J. Melsheimer, R. Schlögl, Identification of reaction products of mild oxidation of H2S in solution and in solid state by UV-vis spectroscopy, Fresenius J. Anal. Chem. 357 (1997) 397-400.

[39] A. Yazdanbakhsh, A. Eslami, G. Moussavi, M. Rafiee, A. Sheikhmohammadi, Photoassisted degradation of 2, 4, 6-trichlorophenol by an advanced reduction process based on sulfite anion radical: degradation, dechlorination and mineralization, Chemosphere 191 (2018) 156-165.

[40] T.N. Das, R.E. Huie, P. Neta, Reduction Potentials of $\mathrm{SO}_{3}{ }^{-}, \mathrm{SO}_{5}{ }^{-}$, and $\mathrm{S}_{4} \mathrm{O}_{6}{ }^{\cdot 3-}$ Radicals in Aqueous Solution, (1999).

[41] X. Liu, S. Yoon, B. Batchelor, A. Abdel-Wahab, Degradation of vinyl chloride (VC) by the sulfite/UV advanced reduction process (ARP): effects of process variables and a kinetic model, Sci. Total Environ. 454-455 (2013) 578-583.

[42] L. Dogliotti, E. Hayon, Flash photolysis study of sulfite, thiocyanate, and thiosulfate ions in solution, J. Phys. Chem. 72 (1968) 1800-1807.

[43] E. Hayon, A. Treinin, J. Wilf, Electronic spectra, photochemistry, and autoxidation mechanism of the sulfite-bisulfite-pyrosulfite systems. $\mathrm{SO}_{2}{ }^{-}, \mathrm{SO}_{3}{ }^{-}, \mathrm{SO}_{4}{ }^{-}$, and $\mathrm{SO}_{5}{ }^{-}$radicals, J. Am. Chem. Soc. 94 (1972) 47-57.

[44] X. Kong, J. Jiang, J. Ma, Y. Yang, W. Liu, Y. Liu, Degradation of atrazine by UV/ chlorine: efficiency, influencing factors, and products, Water Res. 90 (2016) 15-23.

[45] J.C. Carlson, M.I. Stefan, J.M. Parnis, C.D. Metcalfe, Direct UV photolysis of selected pharmaceuticals, personal care products and endocrine disruptors in aqueous solution, Water Res. 84 (2015) 350-361.

[46] B. Xie, C. Shan, Z. Xu, X. Li, X. Zhang, J. Chen, B. Pan, One-step removal of Cr(VI) at alkaline $\mathrm{pH}$ by UV/sulfite process: reduction to $\mathrm{Cr}$ (III) and in situ $\mathrm{Cr}(\mathrm{III})$ precipitation, Chem. Eng. J. 308 (2017) 791-797.

[47] X. Li, J. Fang, G. Liu, S. Zhang, B. Pan, J. Ma, Kinetics and efficiency of the hydrated electron-induced dehalogenation by the sulfite/UV process, Water Res. 62 (2014) 0-8.

[48] C. Sahoo, A.K. Gupta, Optimization of photocatalytic degradation of methyl blue using silver ion doped titanium dioxide by combination of experimental design and response surface approach, J. Hazard. Mater. 215-216 (2012) 302-310.

[49] Y. Mu, G. Wang, H.Q. Yu, Response surface methodological analysis on biohydrogen production by enriched anaerobic cultures, Enzyme Microb. Technol. 38 (2006) 905-913.

[50] N. Biglarijoo, S.A. Mirbagheri, M. Ehteshami, S.M. Ghaznavi, Optimization of Fenton process using response surface methodology and analytic hierarchy process for landfill leachate treatment, Process Saf. Environ. Prot. 104 (2016) 150-160. 